\title{
Breve esbozo de la evolución histórica de las garantías de los derechos fundamentales en Cuba
}

\author{
Brief outline of the historical evolution of the \\ guarantees of fundamental rights in Cuba
}

\author{
Carlos Alberto Alejo Martínez ${ }^{1}$ \\ Universidad de La Habana, Cuba
}

Revista Derechos en Acción ISSN 2525-1678/ e-ISSN 2525-1686

Año 6/NNo 19 Otoño 2021 (21 marzo a 20 junio), 520-547

DOI: https://doi.org/10.24215/25251678e525

Recibido: 01/03/2021

Aprobado: 15/05/2021

Resumen: El presente trabajo versa sobre las garantías de los derechos fundamentales frente al poder sancionador del Estado en el ordenamiento jurídico cubano, realizando un breve esbozo sobre su evolución histórica, con especial atención a lo preceptuado en este sentido en el orden constitucional, desde la etapa colonial hasta el momento de ruptura que constituye la consagración constitucional del debido proceso como garantía de los derechos fundamentales en la Constitución cubana de 2019, así como de las falencias que presenta en este sentido el proceso penal cubano y la necesidad de cambios legislativos a fin de que concuerden con el nuevo texto constitucional de acuerdo a los principios de legalidad, supremacía constitucional y jerarquía normativa a fin de lograr un modelo garantista frente al ius puniendi estatal.

Palabras clave: derechos, garantías, proceso, Constitución, legalidad.

\footnotetext{
1 Licenciado en Derecho por la Facultad de Derecho de la Universidad de La Habana (2017). Juez del Tribunal Provincial Popular de la Habana (2017-2019). Consultor Jurídico TRANSCONSUL S.A. krlsalejo17@gmail.com (https://orcid.org/0000-0001-8516-1580)..
} 
Abstract: The present paper is about the guarantees of fundamental rights against the sanctioning power of the State in the Cuban legal system, making a brief outline of its historical evolution with special attention to what is prescribed in this sense in the constitutional order, from the colonial stage to the present of rupture that constitutes the constitutional consecration of Due Process as a guarantee of fundamental rights in the Cuban Constitution of 2019, as well as of the shortcomings that the Cuban criminal process presents in this regard and the need for legislative changes in order to be consistent with the new Constitutional text in accordance with the principles of legality, constitutional supremacy and normative hierarchy, in order to achieve a guarantee model against the ius puniendi of the State

Keywords: rights, guarantee, Constitution, process, legality.

\section{A modo de Introducción}

La nueva Constitución cubana de 2019 marca un antes y un después en cuanto a la regulación de las garantías de los derechos fundamentales frente el ius puniendi estatal; este magno texto consagra, a diferencia de su predecesora, el Debido Proceso como garantía al individuo, lo que irradia a todo el ordenamiento jurídico teniendo en consideración los principios de supremacía constitucional y jerarquía normativa.

Puesto que el catálogo de garantías que incluye la nueva constitucionalización del Debido Proceso en Cuba debe implementarse mediante las normas jurídicas de inferior jerarquía, se impone la necesidad de la modificación de las Leyes de Procedimiento Penal, el Código Penal y la Ley de Procedimiento Civil, Administrativo, Laboral y Económico, entre otras; normas que se encuentran atemperadas con la derogada Constitución de 1976 y que en varios aspectos entran en contradicción con los postulados constitucionales y las garantías a los derechos fundamentales del individuo consagrados en el nuevo texto constitucional de 2019. 
Cabe preguntarnos ahora, frente a la necesidad de modificar todo nuestro ordenamiento jurídico para que se ajuste a los nuevos postulados constitucionales, cómo llegamos a este momento y cómo han evolucionado las garantías de los derechos fundamentales frente al ius puniendi estatal desde la etapa colonial hasta el punto de inflexión en que se encuentra hoy nuestro Derecho.

Es por lo anterior que consideramos imprescindible conocer nuestros orígenes, quizás por aquel axioma de que quién no conoce la historia está condenado a repetirla.

\section{Algunos conceptos necesarios}

A nivel mundial no existe cuestionamiento alguno sobre el sitio cimero que ocupan estos derechos, así como la trascendencia de su tutela y respeto por parte de los Estados en aras de la plena realización del ser humano en la sociedad moderna. La doctrina dedicada al estudio de los derechos fundamentales es prolífica en definiciones y no desprovista de disquisiciones teóricas a la hora de conceptualizarlos y fundamentarlos. ${ }^{2}$

Una de las definiciones de derechos fundamentales brindada por la doctrina europea contemporánea es la vertida por Ferrajoli, según este profesor italiano, son aquellos derechos universales y, por ello indisponibles e inalienables, que resultan atribuidos directamente por las normas jurídicas a todos en cuanto personas, ciudadanos $^{3}$. La citada definición, de marcado tinte normativista permite introducir el debate sobre la relación intrínseca existente entre Derechos Humanos y derechos

\footnotetext{
2 Ver. NOGUEIRA, Humberto (2003). Teoría dogmática de los derechos fundamentales. Universidad Nacional Autónoma de México. México D.F.; FIORAVANTI, Maurizio (2003). Los Derechos Fundamentales. Apuntes de Historia de las Constituciones. Trotta. Madrid y FERRAJOLI, Luigi (1999). Derechos y Garantías. La ley del más débil. Trotta. Madrid.

3 FERRAJOLI, Luigi, Garantías. (Trad. de Antonio de Cabo y Gerardo Pisarello), Aula Virtual Derecho Procesal Penal. Facultad de Derecho. Universidad Nacional de Mar del Plata. En: (http://procesalpenal.wordpress.com/2007/11/18/garantias-articulo-de-luigi-ferrajoli)
} 
fundamentales, pues aunque comparten las características de universalidad, indisponibilidad e inalienabilidad, introduce además el papel de las normas jurídicas, del Derecho, en el reconocimiento o no de estos, lo que los distingue de los denominados Derechos Humanos.

Por otra parte, en la mentada concepción, Ferrajoli hace referencia al papel del estatus jurídico del ciudadano. Dicho estatus, en su relación con un Estado en concreto, se rige por criterios como ciudadanía, nacionalidad y residencia, del cual se hace depender el reconocimiento por este de determinados derechos fundamentales al individuo. Vale decir que esta concepción rompe con el paradigma de que un derecho de esta naturaleza puede ser reclamado aún y cuando no se encuentre positivado, negando al ciudadano esta posibilidad y por tanto dejándolo desprotegido frente al poder.

En contraposición con este criterio de que son las normas jurídicas las que definen que un derecho sea considerado como fundamental o no, encontramos en la doctrina nacional lo expuesto por Prieto Valdés, quien considera (...) no es el Derecho el que determina que uno u otro derecho sea fundamental, sino que su consideración como tal es resultado del nivel de desarrollo y reconocimiento que hace cada sociedad en correspondencia con aspiraciones y reclamos; aunque tampoco podemos negar la importancia y utilidad del Derecho, a fin de hacerlos efectivos y permitir su defensa frente a terceros ${ }^{4}$.

Otra definición que la doctrina internacional nos ofrece sobre derechos fundamentales es la de Peces Barba, que los define como aquella (...) facultad que la norma atribuye, de protección a la persona en lo referente a su vida, a su libertad, a la igualdad, a su participación política o social, o a cualquier otro aspecto fundamental que afecta el desarrollo integral como

4 PRIETO, Martha (2013). "Una mirada desde y para el ordenamiento jurídico cubano: en defensa de los derechos", en Revista Anales de la Academia de Ciencias de Cuba, Vol. 3, nro. 2, 2013. en: http://www.revistaccuba.cu/index.php/acc/article/view/167/136 
persona, en una comunidad de hombres libres, exigiendo el respeto de los demás hombres, de los grupos sociales y del Estado, y con posibilidad de poner en marcha el aparato coactivo del Estado en caso de infracción. ${ }^{5}$

Este concepto de derechos fundamentales nos introduce al deber que posee el Estado no solo de reconocer y respetar estos al individuo, sino que además debe crear los mecanismos necesarios para que cualquier ciudadano pueda lograr el pleno ejercicio de los mismos, así como reclamar y lograr una satisfacción una vez que aquellos sean lesionados, tanto por la actuación del propio aparato de poder estatal como por actos realizados por una persona natural o jurídica. Así entonces, emergen los mecanismos de protección de los derechos, los que deben permitir al individuo exigir y lograr la paralización de la vulneración a estos, así como la indemnización respectiva y concordante con los efectos del daño causado. Es por ello que a cada derecho que el Estado formule jurídicamente debe corresponderle una garantía consagrada por una norma jurídica.

Por ejemplo, al derecho a la vida le corresponde una garantía normativa que prohíbe matar o lesionar, junto a la determinación de las consecuencias jurídicas por la actuación lesiva y la exigencia de responsabilidad, mientras que a los derechos sociales les corresponden obligaciones de prestación por parte de la Administración Pública y a la vez el derecho a reclamarlos y defenderlos en caso de amenaza, disminución o vulneración.

El término (...) garantía deriva de la idea fundamental de confianza que debe presidir todas las relaciones jurídicas, su finalidad no es otra que la de suministrar: seguridad, protección o defensa (...), ${ }^{6}$ entiéndase en este caso atemperado este concepto a las garantías de los derechos fundamentales del individuo.

\footnotetext{
5 PECES-BARBA, Gregorio (1995). Derechos Fundamentales. Universidad Carlos III. Madrid, p. 1.

6 CUTIÉ, Daniela (1999) El Sistema de Garantías de los Derechos Humanos en Cuba, Tesis presentada en opción al Grado Científico de Doctora en Ciencias jurídicas, Universidad de Oriente, Santiago de Cuba.
} 
Respecto a las garantías también existen diversas posturas y clasificaciones ${ }^{7}$, las que vale analizar en cuanto contribuyen a lograr la efectiva realización de un derecho que se encuentra consagrado en las normas y que además ha sido resultado del mandato democrático de la sociedad que conmina al Estado a la plena satisfacción de los derechos fundamentales de los individuos. Pero también entre las garantías está la obligación de protección, de perseguir y castigar mediante su ius puniendi a aquellas personas jurídicas o naturales que con su actuación vulneran derechos fundamentales de otros.

Gran importancia reviste en este ámbito las garantías sustantivas y procesales frente al Derecho Penal, que permiten la salvaguarda de los derechos en las situaciones que la relación persona-ius puniendi estatal acarrea. Como sentenciara Roxin (...) con la aparición de un derecho de persecución penal estatal, surgió también, a la vez, la necesidad de erigir barreras contra la posibilidad del abuso del poder estatal. El alcance de esos límites es, por cierto, una cuestión de la respectiva Constitución del Estado. ${ }^{8}$ Es este entonces el papel reservado al conjunto de principios, derechos y garantías que conforman al Debido Proceso, el que debe servir de escudo al individuo frente a la aplicación del poder estatal.

Si la función de las garantías es tributar al aseguramiento y defensa de los derechos de la persona incluso durante el proceso, su falta o lesión conlleva a un desequilibrio entre los sujetos de la relación. Así entonces, un sistema de justicia garantista de los derechos consagrados en la normativa constitucional debe prever aquellos medios que, además de permitir la cabal protección de los derechos, tribute a la legitimación de sus propias decisiones y del Estado al que representa, siendo esta la forma de respetar y asegurar los postulados de la norma suprema y fundacional de todo el Sistema de Derecho.

\footnotetext{
7 Ver. FERRAJOLI, Luigi, ob. cit.

8 ROXIN (2008), Derecho Procesal Penal, 25. ${ }^{a}$ ed. Editores del Puerto, Buenos Aires, p. 3.
} 
Partiremos de la idea de que se puede asumir que son derechos fundamentales, en tanto como herramienta de análisis para esta investigación: aquellos derechos que son explícitamente reconocidos y garantizados en un determinado ordenamiento jurídico a la persona, por lo regular en la Constitución, obligando al Estado a su protección, siendo condicionado este reconocimiento por el momento histórico y las situaciones concretas de la sociedad, teniendo en cuenta criterios como la nacionalidad y la ciudadanía para el reconocimiento y protección de algunos de estos derechos.

Es válido entonces definir que la tutela jurídica de los derechos es indispensable como garantía primaria de los mismos en cuanto a su ejercicio, dado que su inclusión en la norma de rango constitucional no solo sirve para reconocerlos al ciudadano, sino que obliga a su respeto por parte del Poder del aparato estatal en su actuación. La tutela jurídica constituye, además, una primera garantía de los derechos en cuanto permite al individuo, sobre esta base reclamar ante cualquier violación que sufra en cuanto a ellos.

La labor de llegar a una definición de garantía, por otra parte, es harto difícil dado las diversas corrientes y opiniones vertidas en la doctrina; sin embrago, existe un aspecto en el que todos coinciden: a pesar de que ambas categorías -derechos y garantías- guardan una intrínseca relación, no pueden confundirse.

Las garantías de los derechos fundamentales son, sin ánimo de ser absolutos, aquellas vías, mecanismos, técnicas o instituciones que tutelan los derechos y libertades fundamentales consagrados constitucionalmente y que permiten su plena protección y realización por parte del individuo, brindándole escudo y reparación ante una vulneración proveniente tanto por parte del Estado como de otras personas naturales o jurídicas; no restringiéndose a la vía judicial; siendo esta sin duda la más importante y efectiva puesto que, es en sede procesal penal que la tutela mediante garantías de los derechos fundamentales 
debe ser más férrea dado el peligro a que se exponen los citados derechos frente a la aplicación del ius punindi estatal.

\section{Breve reseña histórica de las garantías de los derechos fundamentales en Cuba. De la Colonia al Socialismo}

Las garantías de los derechos fundamentales llegan a Cuba desde España como toda institución de Derecho, dado que no es posible hablar ni de Estado ni de Derecho antes de la colonización española de la Isla.

Por medio de la Constitución de Cádiz ${ }^{9}$ llegan las garantías del ciudadano al proceso penal; por primera vez se hace referencia al derecho a ser juzgado por un juez natural (art. 247), se elimina la secretividad en las actuaciones posteriores a la investigación (art.302), se prohíbe la tortura durante la investigación (art.303), entre otras, aunque se instituye que en circunstancias extraordinarias las garantías podrán ser suspendidas por un tiempo determinado (art.308). Pero su corto período de vigencia trajo consigo que tanto los derechos que reconocía como los mecanismos mediante los cuales se garantizaban no se llevaran a la práctica, siendo en realidad inexistentes. No obstante su formulación sirvió de guía al pensamiento posterior tanto en Cuba como en las demás colonias españolas de América que ya comenzaban a luchar por su independencia, reclamando además de su soberanía, el reconocimiento de derechos como los otorgados por las Cortes de Cádiz

No es hasta el 1ro de enero de 1889, con la Ley de Enjuiciamiento Criminal española de 14 de septiembre de 1882, hecha extensiva a Cuba mediante el Real Decreto de 19 de octubre de 1888, junto al Código Penal de 1870 más otras importantes normativas, que se marca el paso del imperio del Derecho feudal al Derecho burgués en Cuba, instituyéndose de paso, algunas garantías en el proceso penal.

\footnotetext{
9 Ver. MATILLA CORREA, Andry y MASSO, Marcos(coordinadores) (2012). De Cádiz (1812) a La Habana (2012). Ediciones ONBC, La Habana.
} 
A juicio de Rivero ${ }^{10}$ este cuerpo legal (Ley de Enjuiciamiento Criminal española de 14 de septiembre de 1882), constituyó un paradigma de proceso para su época, siendo expresión de una mixtura entre las ideas del liberalismo y la costumbre de enjuiciar a los delincuentes mediante un modelo inquisitivo. Entre sus principales notas distintivas de carácter garantista se encuentran la separación de las funciones de instrucción, acusación y juzgamiento, encontrándose la primera etapa o del sumario, permeada de caracteres del sistema inquisitorial y la segunda o del juicio oral, con características dominantes del sistema acusatorio como son la publicidad, la contradicción y la libre valoración de la prueba por parte del Juez. ${ }^{11}$ Por tanto puede considerarse que esta nueva normativa adjetiva constituye un punto de inflexión en las garantías del individuo frente al ius puniendi del Estado en el proceso.

Puesto que desde 1868 y hasta 1898 en Cuba se sucedieron tres guerras por la independencia del país, existieron tres textos constitucionales adoptados por la República de Cuba en armas para regular la vida en las zonas liberadas del yugo colonial español.

Es menester destacar la primera Carta Magna cubana contentiva de garantías en el orden penal, la Constitución de la República en Armas de 1897, conocida comúnmente como Constitución de La Yaya, última de las constituciones mambisas y la primera en poseer una parte expresamente destinada a la tutela de los derechos individuales y a las garantías que debían acompañarlos para su aseguramiento ${ }^{12}$.

Dichas garantías fueron recepcionadas por la posterior Ley Penal de Cuba en Armas de 1898 que consagró principios como

10 RIVERO, Danilo (2012). Ley de Procedimiento Penal, Disposiciones del CGTSP (Comentarios). p. XXVII. Ediciones ONBC.

11 Ibídem., pp. XXVIII.

12 Artículo 4.- Nadie podrá ser detenido, procesado ni sufrir condena, sino en virtud de hechos penados en Leyes anteriores a su comisión y en la forma que las mismas determinen.

Artículo 5.- Ninguna Autoridad podrá detener ni abrir correspondencia oficial o privada, salvo con las formalidades que las Leyes establezcan y por causa de delito 
nullum crimen et nulla poena sine previa lege peonale así como el efecto irretroactivo de las Leyes Penales. ${ }^{13}$

Lo anterior es muestra del profundo interés que despertaban en los legisladores mambises los ideales liberales burgueses en tanto eran expresión garantista frente al poder punitivo del Estado. No era solo la independencia de Cuba el propósito de los mambises, sino también la creación de una República que garantizara mediante sus normas los derechos de sus ciudadanos.

Resulta interesante como se pretendía garantizar estos derechos en un Estado que desde su nacimiento se encontraba en guerra y que no poseía un territorio fijo ni un aparato burocrático con una sede estable, lo cual hacía aún más difícil la consecución de estos objetivos dada las duras condiciones que la situación que la guerra constante imponía. Es cierto además que la mayoría de los derechos expuestos en las constituciones mambisas se encuentran desprovistos de garantías, pero no podría haber sido de otra manera, vale recordar las condiciones bélicas afrontadas por la República de Cuba en Armas durante la vigencia de estos textos.

A inicios de la ocupación norteamericana de Cuba, rigió en la ciudad de Santiago de Cuba la denominada Constitución provisional $^{14}$ o de Leonard Wood, promulgada mediante una orden militar de este general norteamericano el 20 de octubre 1898. A pesar de su efímera vigencia es de destacar el cúmulo de garantías que implantaba en el orden del proceso, como son la gratuidad de la justicia, el derecho a la defensa material y técnica, se implanta el principio de non bis in idem, entre otras garantías como la acción de Habeas Corpus. Recuérdese que este texto provisional solo regía para los territorios ocupados

\footnotetext{
13 Ver: FERNÁNDEZ BULTÉ, Julio. Historia del Estado y el Derecho en Cuba. Capítulo IV. Universidad de la Habana.

14 Constitución provisional de Santiago de Cuba o de Leonardo Wood de 1898 en: Biblioteca Jurídica Virtual del Instituto de Investigaciones Jurídicas de la UNAM, http//www.jurídicas. unam.mx
} 
por el ejército norteamericano antes de la firma del Tratado de París, situados en torno a la ciudad de Santiago de Cuba.

Como parte de la influencia ejercida por el Gobierno de ocupación norteamericano durante el período que abarca la firma del Tratado de París en 1898 y el nacimiento de la República en Armas el 20 de mayo de 1902, en sede de las garantías de los derechos fundamentales se experimentó una reforma, vale decir que beneficiosa.

En ese período encontramos las modificaciones introducidas a la Ley de Enjuiciamiento Criminal mediante órdenes militares que influyeron, cabe decir que beneficiosamente, en las garantías de los derechos: una referida al recurso de casación (Orden No.92 de 1899), otra que abolió casi por completo el secreto sumarial (Orden No. 109 de 1899) y la que estableció el Hábeas Corpus, la Orden No.427 de 1900. Todas estas constituyeron mejoras a la posición del acusado durante el proceso penal, en especial el Hábeas Corpus, institución que a pesar de poseer una raíz romana nos llega proveniente del Derecho anglosajón y la que consideramos eminentemente garantista de los derechos individuales, en especial de la vida y la libertad del individuo.

Luego del establecimiento de la República con la declaración de independencia el 20 de mayo de 1902 la tutela de las garantías de los derechos fundamentales evolucionó tal y como se expondrá a continuación.

La Constitución de $1901^{15}$, tan tristemente célebre para todos los cubanos dado que da nacimiento a una República con su libertad cercenada por la Enmienda Platt, es considerada como una de las últimas constituciones liberales del mundo. Según

\footnotetext{
15 Para más información sobre la Constitución de 1901 ver: UGARTE, Ángel (1918). Comentarios a la Constitución Cubana. Compañía Biográfica, La Habana, P. 28 en https://ufdc.ufl. edu/AA00061317/00001/33x; LAZCANO y MAZÓN, Andrés (1952). Historia y Textos de las Constituciones de la República de Cuba. Ediciones Cultura Hispánica, Madrid; BAHAMONDE RODRÍGUEZ Santiago (2019). “EI Constitucionalismo Cubano. Retrospectiva Histórica a Siglo y Medio", en www.seapcuba.cult.cu/wp-content/uploads/2019/06/
} 
Hernández Corujo ${ }^{16}$ esta fue una Constitución de corte individualista de acuerdo con los principios de la filosofía política del siglo XIX y (...) situó una serie de derechos que garantizaba (...), a través de tres secciones: una sobre derechos individuales, otra relativa al derecho de sufragio y otra sobre suspensión de las garantías constitucionales. ${ }^{17}$

En materia de garantías de los derechos individuales, con influencia de Europa y de los Estados Unidos, incluyendo las ideas liberales de que eran portadores los antiguos mambises, se consagra la igualdad de los cubanos ante la Ley, no reconociéndose fueros ni privilegios personales (art.11) y se reconoce la irretroactividad relativa de la Ley penal en pos del beneficio del acusado (art.12). De la misma manera, se prohíbe por esta Constitución la detención del individuo sino en los casos y en la forma que prescribe la Ley (art.15), se prohíbe además que los detenidos sufran más de 24 horas de prisión sin ser entregados al juez o tribunal competente (art.16), de igual forma se establece un plazo de 72 horas para dejar sin efecto o elevar a prisión al detenido puesto a disposición del juez o tribunal competente (art.17).

En virtud de este texto, es solo a competencia de los órganos judiciales la capacidad de aplicar la prisión provisional (art. 18), se establecen principios como el de juez natural y el nullum crimen et nulla poena sine previa lege peonale (art. 19), se prescribe que el incumplimiento de estas formalidades conllevará la libertad del detenido, estableciéndose aunque no con este nomen iuris la posibilidad del ejercicio del Hábeas Corpus (art.20) y se proscribe la obligatoriedad de la declaración contra sí mismo, su cónyuge y los parientes dentro del cuarto grado de consanguinidad o segundo de afinidad (art. 21).

El texto analizado consagró una garantía para los derechos en ella contentivos según lo establecido en artículo 37 , la que

16 HeRnÁNDEZ CORUJO, Enrique (1960). Historia Constitucional de Cuba. Tomo II. Compañía Editora de Libros y Folletos. La Habana.

17 Ibídem., p. 28 
se conoce como de contenido esencial, exponiendo qué serán nulas las Leyes que regulen el ejercicio de los derechos que la Constitución contenga si las citadas normas los restringen, disminuyen o adulteren. Es contentivo este artículo, aunque no expresamente, de otra garantía de los derechos individuales, la reserva de Ley. Esta garantía consistía en que solo las normas con rango de Ley como producción normativa del Poder Legislativo podían modificar los derechos consagrados constitucionalmente, así como sus garantías. Con esto se buscaba que el ejecutivo no pudiera restringir o modificar el contenido de los derechos, libertades y garantías consagradas constitucionalmente.

Es factible entones afirmar, mediante el análisis de estos artículos que los constituyentes de 1901 veían con especial interés la necesidad imperiosa de poner coto al ius puniendi del Estado que creaban mediante la redacción de esta Carta Magna, esbozando, con las limitaciones que el propio momento histórico imponía, garantías a las libertades individuales que las ideas liberales defendidas por ellos reconocían, configurando reglas de actuación cercanas al concepto de Debido Proceso, que junto las garantías presentes en los artículos 22 y 23 referentes a la inviolabilidad de la correspondencia y del domicilio respectivamente, protegían los derechos que la propia Constitución reconocía a los ciudadanos de la naciente República.

Como no podía faltar en una constitución de corte liberal, el texto de 1901, que entraría en vigor al año siguiente, era contentivo de garantías dedicadas a la protección de la propiedad y de su libre ejercicio, de los que en particular interesa para el tema abordado, el artículo 33, en el que se prohíbe la confiscación de bienes como pena, lo cual suponía una garantía para este derecho.

Las regulaciones emanadas de la Constitución de 1901, anteriormente expuestas, sientan las bases, a pesar de no reconocerlo expresamente, de la concepción del Debido Proceso en nuestra República, dado que introducen con rango constitucional muchos de los elementos esenciales de esta institución. 
Durante los últimos estertores de esta Constitución, las garantías en ella incluidas, así como todo su contenido fue violentado durante la dictadura de Gerardo Machado, por lo que sobrevinieron una serie de normas que no aportaron en cuanto a las garantías de los derechos fundamentales. ${ }^{18}$

No fue hasta la promulgación de la Constitución de 1940 que se realiza un avance significativo tanto en la tutela de los derechos fundamentales como en el establecimiento de garantías, como consecuencia de la lucha mundial contra el fascismo y luego de la Revolución del 30 que derrocó al tirano Machado, período durante el cual las garantías a los derechos fundamentales fueron obviadas en innumerables ocasiones. En consonancia, ciertamente, con los desmanes que sufrió el pueblo durante la dictadura de los años anteriores, así como la influencia de los sectores más progresistas de la sociedad cubana de la época en la redacción del texto constitucional de 1940, la configuración de las garantías constitucionales de los derechos individuales en relación con el proceso penal es indiscutiblemente la más detallada y amplia que ha conocido texto constitucional cubano hasta nuestros días.

Su artículo 20 refrenda la igualdad ante la Ley, así también el artículo 21 estableció la irretroactividad relativa de la Ley penal excluyendo del beneficio de la retroacción de la Ley más benévola a los funcionarios o empleados públicos que delinquen en el ejercicio de su cargo y a los responsables de delitos electorales y contra los derechos individuales, imponiéndose a estos la norma vigente al momento de delinquir; lo que en relación con esta investigación constituye un importante antecedente. El artículo 26 por su parte consagró el principio de presunción de inocencia, el cual además estableció que la norma adjetiva penal debía establecer las garantías necesarias para que todo delito

\footnotetext{
18 Para un mayor acercamiento y análisis de estas normas ver: HERNÁNDEZ, Enrique, ob. cit.; VILLABELLA ARMENGOL, Carlos Manuel (2009). Historia Constitucional y poder político en Cuba. Editorial Ácana, Camagüey; MULET MARTínEZ, Fabricio (2014). “El desarrollo constitucional en Cuba durante los años 1933-1939". Revista Cubana de Derecho IV Época, número 43, enero-julio de 2014. Editorial UNIJURIS, La Habana.
} 
fuere probado con independencia de la declaración emitida por el acusado. He aquí una garantía esencial, la no incriminación, junto al impedimento consecuente para el juez de fallar con esta simple declaración.

También este artículo configuró toda una serie de garantías para los detenidos como la publicidad del registro de detenidos y presos, la prohibición de la incomunicación de estos e incluso configura diversos supuestos de responsabilidad penal para los encargados de la custodia de estos individuos con el fin de evitar la tortura y las ejecuciones sumarias ocurridas durante la anterior dictadura.

Igualmente, el artículo 27 impone el límite de 24 horas para la detención antes de ser el detenido puesto a disposición del órgano judicial competente o en libertad, así como el término de 72 horas para que el propio órgano judicial dictara prisión preventiva como medida cautelar o libertad. Sobre la prisión preventiva se ordena que se cumpla separada de los ya sancionados, no estando expuestos los detenidos ni a trabajos ni al reglamento de los sancionados.

De suma importancia constituye la consagración en el artículo 28 del principio de juez natural y el de nullum crimen et nulla poena sine previa lege peonale. Además, este prescribe la no obligatoriedad de declaración contra sí mismo o contra su cónyuge y los parientes dentro del cuarto grado de consanguinidad o segundo de afinidad, y la prohibición de dictar sentencia contra el acusado rebelde, ni contra el que no ha podido ser oído durante el proceso.

Importante garantía jurisdiccional lo fue la acción de Habeas Corpus configurada por el artículo 28 de la Constitución de 1940 de modo que nada impidiera su ejecución. El citado precepto también se pronuncia en cuanto que la declaración obtenida mediante coacción o violencia que quedaba prohibida y por tanto era declarada nula.

Asimismo, la inviolabilidad del secreto de correspondencia y de los demás documentos privados es protegido por el artículo 
32 constitucional, el cual solo admite su violación cuando mediara un auto fundado del juez competente, esta garantía se hace extensiva a las comunicaciones telegráficas, telefónicas y cablegráficas. Por su parte la garantía de inviolabilidad del domicilio es configurada por el artículo 34.

Existen otras garantías en el texto de 1940 de tipo normativo o abstracto, y que también tributan a las garantías de los derechos fundamentales y al contenido del Debido Proceso, tal es el caso de la recogida en el artículo 40 de dicho texto donde se establece el carácter ilegislable de los derechos, en referencia a los posibles ataques desde el ejecutivo, en cuanto a su restricción o modificación, muestra de la experiencia de la joven República en cuanto a los desmanes del dictador Machado. No se aprecia en dicho precepto la reserva de ley clásica de los derechos, ya que expone que los derechos podrán ser desarrollados, no restringidos, repito, por actos normativos, no estableciendo a la Ley como único mecanismo para este propósito.

Aunque pudiera calificarse de cuasi perfecta la configuración de las garantías constitucionales establecidas por la Constitución del 40 en todos los ámbitos, la situación del país, así como la poca voluntad política en el orden legislativo de desarrollar los postulados en ella contenidos, llevó a que muchas de las conquistas plasmadas en esta Carta Magna sufrieran una casi nula aplicación.

Sin lugar a dudas, la violación de las garantías constitucionales de la Constitución de 1940 fue absoluta durante el imperio de los Estatutos Constitucionales impuestos por el gobierno golpista encabezado por Fulgencio Batista desde 1952; por solo citar dos ejemplos tenemos las violaciones cometidas durante el proceso llevado contra los asaltantes al Moncada, denunciados magistralmente por Fidel Castro en La Historia me Absolverá y las ejecuciones sin previo juicio perpetradas por la tiranía hasta su derrocamiento. Valga recordar que los que se rebelaron en armas contra el régimen se encontraban amparados por el 
derecho de la legítima resistencia que la vejada Constitución del 40 consagraba en su artículo 40, garantía denominada como extrajurídica ${ }^{19}$.

A raíz del triunfo revolucionario en enero de 1959, el 7 de febrero entra en vigor, la Ley Fundamental de 1959, con el fin de suplir la carencia de una Constitución, dado que los ilegales Estatutos Constitucionales de Batista eran inoperantes en el nuevo contexto histórico.

La Ley Fundamental de 1959 restauró la Constitución de 1940, con aquellas modificaciones necesarias para su adaptación al nuevo contexto y programa socioeconómico y político que se avecinaba con el triunfo revolucionario. El Título IV mantiene la denominación de Derechos Fundamentales, bajo el principio de progresividad reconocido por las Constituciones de $1901 \mathrm{y}$ 1940; dedicando la sección primera a los derechos individuales o civiles y políticos.

Entre las modificaciones más importantes que se le realizaron mediante esta Ley a la Constitución de 1940, se encuentra la contenida en el artículo 21, en cuanto a la retroactividad de las leyes penales, donde se establece la aplicabilidad de la ley penal, tomando como base su especial promulgación, a los incursos en delitos cometidos en servicio de la tiranía con el objetivo de que el brazo de la justicia revolucionara alcanzara a todos aquellos esbirros y asesinos al servicio del gobierno de facto recién derrocado, no dejando impunes los crímenes cometidos durante la dictadura. El artículo 24 que prohibía la confiscación de bienes, se modifica autorizándola para los bienes del tirano depuesto, los bienes de sus colaboradores y los que pertenezcan a autores de delitos contra la economía nacional o que supongan un enriquecimiento ilícito en consonancia con lo antes expuesto para proveer de un marco legal que legitimara la actuación de la justicia revolucionaria.

19 INFIESTA, R. (1950). Derecho Constitucional. Imprenta P. Fernández y Cía, La Habana, pp. 281-288. 
La institución de Habeas Corpus se mantuvo diseñada de igual forma que en su predecesora del 40, refrendándola en su artículo 29. Vale recalcar que, por disposición de la Ley del Gobierno Revolucionario de 30 de enero de 1959, esta garantía se mantuvo suspendida por un período de 90 días respecto a las personas sometidas a la jurisdicción de los recién creados Tribunales Revolucionarios, encargados de juzgar los crímenes de la depuesta dictadura. Se incluyen además en la citada Ley fundamental las garantías normativas de los derechos fundamentales referentes al derecho de resistencia y al carácter ilegislable de los derechos en cuanto a su restricción o eliminación.

En materia penal, en Cuba luego del triunfo revolucionario de 1959 se mantuvo con algunas modificaciones la ya añeja Ley de Enjuiciamiento Criminal española que había tenido un período de vigencia de 85 años. Esta normativa fue derogada por la Ley de Procedimiento Penal de 1973, la que supuso algunos avances y también algunos retrocesos en cuanto a la configuración del Proceso Penal y que inciden directamente en las garantías de los derechos fundamentales. A juicio de Rivero García ${ }^{20}$ uno de los cambios fundamentales introducidos por la nueva norma fue la supresión de la figura del Juez de instrucción; repartiéndose entre la Policía, el Fiscal y el Tribunal sus antiguas funciones; además de reducen los términos y los plazos, creándose también un procedimiento sumarísimo, el cual solo podría utilizarse de forma excepcional. Uno de los cambios que incidieron en las garantías del acusado durante el proceso es la sustitución del auto de procesamiento que se dictaba ante la existencia de indicios de delito y que convertía al acusado en parte del proceso con los consiguientes derechos y garantías que se derivan de esta condición, por el denominado auto de aseguramiento, que no trae aparejado el establecimiento del acusado como parte y por tanto cercenaba el derecho a la defensa del imputado.

20 RIVERO GARCÍA, Danilo (2012). Estudios sobre el Proceso Penal. Ediciones ONBC. La Habana, pp. 6-7 
Uno de los avances de la LPP de 1973 en comparación a su predecesora, según el citado autor, es que a la luz de la nueva normativa todas las sentencias eran recurribles, pues los recursos venían cercenando en la LECrim en cuanto esta los negaba para los fallos de la denominada justicia correccional. También se simplificó el recurso de casación, eliminándose una serie de formalidades, pero permaneció solamente dedicado a la impugnación de sentencias en cuanto a errores en el procedimiento o la aplicación del Derecho. La nueva normativa, además, reformuló la revisión como un procedimiento y no como un recurso como su predecesora, atemperándola a casos que realmente pudieran darse en la práctica. Uno de los principales cambios introducidos fue en la función del Fiscal que pasa de ser mero acusador al encargado de la defensa y vigilancia del irrestricto cumplimiento de la legalidad socialista, ampliándose sus facultades y atribuciones ${ }^{21}$, lo que a la postre incidió en el desbalance entre las partes en el Proceso Penal que aún hoy perdura en nuestro país.

Luego de este somero panorama que se ha expuesto sobre la evolución histórica de las garantías de los derechos fundamentales en relación con el poder punitivo estatal en la normativa patria debemos analizar la configuración que presentan a día de hoy.

\section{De la Constitución Socialista de 1976 al presente}

Luego de 17 años de provisionalidad revolucionaria nació en 1976 la primera Constitución de carácter socialista de América. Dicha Constitución luego de tres modificaciones (1978,1992 y 2002) rigió nuestros destinos como nación durante un período de vigencia de más de 40 años. Texto revolucionario y adelantado a su época consagró las principales conquistas sociales del pueblo cubano, por demás dichoso del disfrute de muchos 
derechos inexistentes para los demás habitantes de América Latina, sumergida en un período oscuro marcado por dictaduras militares.

En el artículo 41 se hace referencia al principio de igualdad ante la Ley, aunque no de forma expresa sino aplicando una interpretación extensiva de la norma cuando esta establece que todos los ciudadanos gozan de iguales derechos y deberes.

El artículo 56 consagra la inviolabilidad del domicilio salvo los casos previstos en Ley, así como el artículo 57 establece la inviolabilidad de las comunicaciones privadas, entiéndase tanto las telefónicas, cablegráficas, telegráficas y convencionales (correspondencia), en lo que a priori es una frugal transcripción de lo previsto en la Constitución del 40, y que no estable los límites a la intervención por parte de las autoridades de los medios de comunicación, ya sea en proceso investigativo o no, quedando el enunciado con un carácter programático, desarrollándose la regulación de los procedimientos en la norma adjetiva penal que se analizará posteriormente.

En consonancia con lo antes descrito, vale decir que la regulación constitucional de este tema, merecía perfeccionamiento dado el avance experimentado por las telecomunicaciones y el uso de internet en la actualidad, pues la obtención de pruebas por estas vías incide directamente en la vulneración del Debido Proceso. Una parca regulación sobre este contenido dejó abierta brechas en el derecho a la privacidad del individuo y por tanto a la utilización de estas comunicaciones en su contra como pruebas durante un proceso penal; normalmente la violación de este tipo de comunicaciones por parte del aparato estatal encargado de la investigación delictiva queda a juicio de una autoridad jurisdiccional, única capacitada para autorizar este tipo de procedimientos, tema que se abordará posteriormente y que funciona de distinta forma en nuestro país.

Las garantías correspondientes a la libertad y a la integridad en cuanto a la detención se encuentran en el artículo 58 constitucional, previstas para todos los que residen en el territorio 
nacional. Nótese que en este caso no se circunscribe la garantía solo a los ciudadanos, pues en el texto se toma el criterio de la residencia; ahora bien, en nuestro país existe una gran cantidad de personas que nos visitan en concepto de turistas, los cuales, ciñéndonos a lo anteriormente expresado quedan fuera de la tutela de esta garantía, pues tampoco quedarían protegidos por el artículo 34 del texto que equipara en una serie de preceptos a los extranjeros residentes en el país con los cubanos. Del Habeas Corpus y su exclusión de la Constitución de 1976 se ha dicho que:

(...) Mirada especial requiere el habeas corpus, por cuanto no tiene tutela constitucional como resultado de posturas idealistas acerca de la actuación del ser humano, sea funcionario o autoridad competente, y si la merece, incluso su reformulación de manera que se potencie, con un papel rector de la intervención judicial. ${ }^{22}$

El artículo 59 es contentivo de una serie de principios que pertenecen al contenido esencial del Debido Proceso pero que distan mucho de configurarlo, entre estos principios encontramos el derecho al juez natural ya que consagra que solo se podrá ser encausado o condenado por tribunal competente, tomando en cuenta normas cuya vigencia sea previa al delito y que siempre deben mediar las formalidades y las garantías que las propias normas establecen para estos casos. Se consagró por demás, en este artículo, el derecho a la defensa del acusado, no estableciéndose taxativamente la distinción necesaria entre defensa material y defensa técnica, y se proscribe la obtención de cualquier declaración cuando haya sido aplicada violencia o coacción sobre el declarante, estableciendo el carácter de nula para dicha declaración, así como responsables a los perpetradores de la violencia o coacción.

22 PRIETO, Martha (2016). "Las garantías de los derechos fundamentales y la Constitución de 1976", en MATILLA CORREA, Andry (coordinador) La Constitución cubana de 1976: cuarenta años de vigencia. Editorial UNIJURIS. La Habana, p. 185. 
Contrariamente a como se consagra hoy en la mayoría de los textos constitucionales en América Latina, el texto cubano de 1976 instituyó la confiscatoriedad de bienes en su artículo 60, sin exigir expresamente que debe ser resultado de decisión judicial, al plantear que solo procederá la confiscación de bienes cuando esta derive de una sanción emitida por la autoridad competente y en la forma y los casos que la norma contemple.

Otra garantía es la contenida en el artículo 61; el principio de irretroactividad relativa de la norma penal, universalmente reconocido y que establece la irretroactividad de la norma penal, salvo en los casos que sea beneficiosa para el reo.

El sistema de tribunales en cuanto a las garantías de los derechos fundamentales, no existiendo en nuestro panorama la jurisdicción constitucional, ha quedado competente solo para la observancia de la legalidad, por lo que las garantías han quedado reducidas a las denominadas como generales o medios procesales ordinarios, a través de los cuales se protegen los derechos del individuo según la estructuración que la norma brinde a cada tipo procesal, el Civil, el Penal, el Administrativo, etc.

La recepción en Cuba de los instrumentos jurídicos internacionales en este tema puede palparse en la firma y ratificación de la Convención contra la Tortura y otros tratos o penas crueles, inhumanas o degradantes que entró en vigor en $1987^{23}$; una muestra de la acogida de dicho instrumento es la ausencia de este tipo de sanciones en nuestra normativa penal.

La Ley No.5 aprobada por la Asamblea Nacional del Poder Popular el 13 de agosto de 1977, Ley de Procedimiento Penal vigente hasta nuestros días, modificada por los Decretos Leyes No. 87 de 1985, No. 128 de 1991, No. 151 de 1994, y No. 208 del año 2000, entre otras; es la normativa adjetiva penal que rige en nuestro país y es en sus artículos donde descansan la

23 Ver. Convención contra la Tortura y otros tratos o penas crueles, inhumanas o degradantes http://libraryresources.unog.ch/torture 
mayoría de las garantías de los derechos fundamentales durante el proceso de esta naturaleza.

Se ha dicho que aún y cuando existen algunas diferencias entre este cuerpo legal y su antecesor de 1973 son en esencia casi iguales en su estructura y contenido, diferenciándose en cuanto a la atemperación de la nueva normativa a la organización de los Tribunales Populares derivada del fin de la provisionalidad, en algunas modificaciones en cuanto al aseguramiento del acusado y a la redefinición de la competencia de los Tribunales Militares.

En su artículo 1 se consagran una serie de principios que deberían haber sido consagrados constitucionalmente y que funcionan como garantías de los derechos, este es el caso de la presunción de inocencia, consagrándose además que solo podrá imponerse sanción o medida de seguridad de acuerdo a las normas que esta Ley consagra y en virtud de resolución dictada por tribunal competente, principios del Derecho Penal que se abordarán en el siguiente epígrafe como contenido del Debido Proceso.

En cuanto a la actividad probatoria el citado artículo instituye que todo delito deberá ser probado, con independencia del testimonio del acusado su cónyuge y los parientes dentro del cuarto grado de consanguinidad o segundo de afinidad, cuya sola declaración, no exime de la obligación de práctica de pruebas para la comprobación de los hechos. Aquí observamos la introducción del principio de no autoincriminación que, como anteriormente hicimos referencia en el análisis de la Constitución de 1940, pasó de poseer tutela constitucional a ser refrendado en una norma de menor jerarquía con todas las consabidas consecuencias que acarrea.

La institución de recursos de apelación en el artículo 58 de la citada norma en cuanto a las sentencias de los Tribunales Municipales Populares, los autos de los Tribunales Provinciales Populares que deniegan o rechazan de plano las solicitudes de Habeas Corpus, las sentencias que impongan pena de 
muerte y las sentencias dictadas en juicios celebrados por el procedimiento abreviado, constituyen garantías en cuanto permiten el juzgamiento en doble instancia para el primer y cuarto supuesto y para el segundo y tercer supuesto garantizan la integridad física, la libertad y la vida.

El establecimiento de los recursos de casación en los casos de infracción de ley o quebrantamiento de forma, previstos en el artículo 68 de la LPP, también podrían considerarse garantías a los derechos cuando se ha sancionado sin respetar el principio de legalidad, pero a los sancionados en primera instancia en los Tribunales Provinciales Populares no se les brinda la garantía del juzgamiento en doble instancia pues de no concurrir los supuestos previstos por la casación, no procederá recurso sobre la pena ante instancia superior.

El artículo 109 de la LPP, consagra la obligación del fiscal en la fase preparatoria del juicio oral, como responsable de la legalidad socialista, y que deben respetarse durante el proceso de investigación e instrucción, todos los derechos de la persona, así como que durante esta fase es obligatorio el apego de la autoridad a las normas que regulan estos procedimientos. Otra de las garantías, en este caso tutelando la libertad individual, se encuentra presente en nuestra LPP en su artículo 241, derivada del artículo 58 de la Constitución vigente referente a la detención y aseguramiento, cuando se expresa que nadie puede ser detenido sino en los casos y con las formalidades que la Ley exige. Esta garantía se encuentra desarrollada en los artículos que le preceden configurándose una serie de términos que en nada benefician al individuo el cual puede pasar 7 días detenido sin que medie ninguna acusación sobre él.

De lo anteriormente expuesto se deriva una primera falencia en cuanto a las garantías de los derechos fundamentales que posee nuestra Ley de Procedimiento Penal (LPP), en especial relacionada con el derecho a la defensa: el abogado entra al sumario solo después de que se ha aplicado una medida cautelar al acusado, período que puede llegar a ser de hasta siete 
días después de realizada la detención (...) o en caso contrario, queda reservada su presencia para la fase que sigue a la calificación, una vez concluida toda la etapa preparatoria y admitido el expediente por el tribunal para el juicio oral, lo cual implica que el imputado estuvo ausente de participar en el procedimiento investigativo seguido en su contra y solo entra en la fase judicial previa al juicio oral. ${ }^{24}$ Es decir, el acusado solo adquiere la condición de parte en el Proceso Penal una vez se le aplica medida cautelar, lo que le cercena sus derechos y garantías durante una parte esencial de la fase preparatoria del Juicio Oral, negándose la asistencia letrada incluso durante el período que puede estar detenido bajo interrogatorio por parte de la Instrucción.

Otro de los principales problemas que posee el Proceso Penal cubano en cuanto a las garantías de los derechos fundamentales es durante la actividad probatoria. Es común que la búsqueda de pruebas que sustente la acusación se realice durante la denominada etapa inicial o fase preparatoria del Proceso Penal, donde solo participan las autoridades policiales, entiéndase policía o instructor, controlados en su actuación por la Fiscalía. Nótese que no media en nuestro modelo la actuación de un ente imparcial como fue el Juez de Instrucción en la LECrim.

Un ejemplo claro de cómo se vulneraron las garantías que recogía nuestra propia Constitución de 1976 por normas de inferior jerarquía lo constituyó la configuración de la actividad probatoria en cuanto a la inviolabilidad del domicilio y de las comunicaciones (artículos 55 y 57 de la Constitución de 1976). De la disposición que la LPP hace de la práctica de pruebas de registro en domicilio privado, en sus artículos 218 al 222, se denota que puede decretarse tanto por el Instructor o por el

\footnotetext{
24 MENDOZA, Juan. Notas para..., en MEDINA, Arnel (coordinador). El Derecho Penal de los inicios del siglo XXI en la encrucijada entre las garantías penales y el expansionismo irracional. Ediciones ONBC. 2014, pp. 192-193
} 
Fiscal, solo con el requisito de que exista algún indicio delictivo, lo cual en la práctica puede ser una simple denuncia, no sometiéndose a una autoridad neutral como puede ser un miembro de los órganos encargados de impartir justicia el cuál decida sobre la procedencia de este tipo de operaciones. Caso idéntico ocurre con el registro de libros y documentos y la apertura y retención de correspondencia, donde igualmente su pertinencia se hace depender de la frase indicios suficientes (artículo 228 de la LPP) y la autoridad que puede disponer incluso la remisión de copias por parte de cualquier operador de comunicaciones es el Instructor o en casos extraordinarios la Policía.

La LPP, dejó en manos de la Fiscalía la adopción de la medida cautelar, con una revisión judicial inmediata. A partir de 1994 a raíz del Decreto Ley. 151 de 10 de junio, modificativo de la citada norma adjetiva, las medidas cautelares pasaron a ser competencia policial y de la instrucción, exceptuando solo la prisión provisional que queda a partir de este momento en manos del fiscal ${ }^{25}$. De esta manera se desterró de Cuba todo control judicial sobre el aseguramiento del imputado, lo que consideramos una flagrante violación a los derechos fundamentales en sede del proceso penal. Se cercena el derecho a la defensa en este caso dado que no media ningún procedimiento oral y contradictorio en la imposición de medida cautelar, en el cual se acredite por las partes, la existencia o no, en el caso concreto, de los presupuestos reconocidos en la norma que fundamenten la detención preventiva. ${ }^{26}$

Otra de las principales falencias garantistas presentes en nuestra LPP es la comúnmente conocida fórmula del artículo 350. A juicio de Rivero García ${ }^{27}$ la raíz histórica de esta institución se encuentra en el artículo 733 de la LECrim de 1882

\footnotetext{
25 Ver: MENDOZA, Juan. Notas para una reforma del derecho a la defensa en el proceso penal cubano, en: MEDINA, Arnel (coordinador), ob.cit.

26 Ídem, p. 193

27 Rivero, Danilo, ob. cit., p. 151
} 
cuyo fundamento fue y se mantiene siendo (...) impedir que la justicia quede en manos de las partes acusadoras, que no han sabido o no han querido calificar en los términos debidos. ${ }^{28}$

En resumidas cuentas, la configuración de la llamada fórmula en el artículo 350 de la LPP, a nuestra consideración, rompe con la imparcialidad del tribunal, una de las principales garantías de los derechos fundamentales del individuo durante el proceso. Principio este, de imparcialidad, que es presupuesto indispensable de cualquier concepción de Debido Proceso, como analizaremos posteriormente.

Siguiendo a Mendoza Díaz ${ }^{29}$, otro de los desatinos del proceso penal cubano radica en cuanto al derecho a la defensa, pues en la fase de ejecución de la sentencia el abogado no participa, por lo que el sancionado queda en manos de las autoridades y normas carcelarias, solo bajo el control de la Fiscalía, encargada de velar por el cumplimiento de la legalidad en dichos establecimientos.

Como se ha podido observar de este parcial análisis de LPP cubana, la situación de las garantías de los derechos fundamentales como coto al ius puniendi estatal es más que precaria y necesitada de una reforma que la adecue a los principios integradores del Debido Proceso.

\section{A modo de conclusión. La Constitución de 2019 y la necesidad de modificación del ordenamiento jurídico}

La Constitución de 2019, fue llevada a referéndum el 24 de febrero de 2019, coincidiendo con la fecha de reinicio de las guerras por la independencia nacional y fue aprobada con el $86,85 \%$ de los votos; entrando en vigor a partir del 10 de abril del propio año, cuando se cumplían 150 años de la proclamación de la Constitución de Guáimaro, primera Carta Magna cubana.

\footnotetext{
28 Ibídem., p. 152

29 MENDOZA, Juan, Notas para..., ob. cit., p. 196
} 
Esta nueva norma fundamental contiene un catálogo mayor de garantías frente al ius puniendi estatal que su predecesora y agrega al Debido Proceso como garantía constitucional de los derechos fundamentales; por tanto, es imprescindible la modificación de las normas de inferior jerarquía a fin de implantar realmente un Debido Proceso en sede penal en Cuba y que los postulados constitucionales actuales no sufran el destino de aquellos consagrados en 1940 que quedaron en letra muerta.

Lo cierto es que a pesar de que la nueva Constitución lleva más de un año vigente, el proceso penal cubano sigue pecando de las falencias garantistas que poseyó bajo el imperio de la Constitución de 1976 lo que impone un desafío y un mandato al órgano legislativo cubano, la Asamblea Nacional del Poder Popular de atemperar las normas de adjetivas a lo establecido en la Ley Fundamental del Estado, pues cada proceso penal que se sustancia bajo el imperio de las leyes vigentes, violenta los principios del Derecho: legalidad, supremacía constitucional y jerarquía normativa, al no haberse desarrollado los postulados constitucionales y no haberse aplicado la Constitución como norma directa.

Aunque reconocemos que el Cronograma Legislativo de la Asamblea Nacional del Poder Popular ha sufrido de atrasos justificados debido a la pandemia de Covid-19, es harto necesaria la protección de los derechos fundamentales imponiéndose la necesidad, hoy más que nunca de modificar nuestro ordenamiento jurídico hacia un modelo garantista de los derechos fundamentales frente al ius puniendi estatal, tal y como mandata nuestra nueva Carta Magna. 